University of Nebraska - Lincoln

DigitalCommons@University of Nebraska - Lincoln

Agronomy \& Horticulture -- Faculty Publications

Agronomy and Horticulture Department

3-1982

\title{
Divergent Selection for Hydrocyanic Acid Potential in Sudangrass
}

Herman J. Gorz

United States Department of Agriculture

Francis A. Haskins

University of Nebraska-Lincoln, fhaskins@neb.rr.com

K. P. Vogel

United States Department of Agriculture, kvogel1@unl.edu

Follow this and additional works at: https://digitalcommons.unl.edu/agronomyfacpub

Part of the Plant Sciences Commons

Gorz, Herman J.; Haskins, Francis A.; and Vogel, K. P., "Divergent Selection for Hydrocyanic Acid Potential in Sudangrass" (1982). Agronomy \& Horticulture -- Faculty Publications. 239.

https://digitalcommons.unl.edu/agronomyfacpub/239

This Article is brought to you for free and open access by the Agronomy and Horticulture Department at DigitalCommons@University of Nebraska - Lincoln. It has been accepted for inclusion in Agronomy \& Horticulture -Faculty Publications by an authorized administrator of DigitalCommons@University of Nebraska - Lincoln. 


\title{
Divergent Selection for Hydrocyanic Acid Potential in Sudangrass ${ }^{1}$
}

\author{
H. J. Gorz, F. A. Haskins, and K. P. Vogel ${ }^{2}$
}

\begin{abstract}
Alteration in hydrocyanic acid potential (HCN-p) of the forage is one of the important objectives in sudangrass [Sorghum sudanense (Piper) Stapf] breeding programs. The effectiveness of recurrent phenotypic selection for increasing or decreasing $\mathrm{HCN}-\mathrm{p}$ in sudangrass was evaluated in two cycles of individual plant selection in the cultivar 'Greenleaf'. In cycle $1, \mathrm{HCN}$ $p$ means of the high and low populations were higher and lower, respectively, than for Greenleaf, but only the low-HCN-p population was significantly different from Greenleaf. In cycle 2, mean HCN-p values of both populations differed significantly from Greenleaf. The average realized heritability for the two cycles was 0.40 while broad-sense heritability estimates averaged 0.86 . After two cycles of selection, the low and highHCN-p populations differed from Greenleaf by about 17 and $30 \%$, respectively.
\end{abstract}

Additional index words: Prussic acid, Dhurrin, Forage quality, Heritability, Sorghum sudanense.
Qudangrass [Sorghum sudanense (Piper) Stapf] and sorghum-sudangrass hybrids are used extensively to provide supplementary feed to animals as pasture or greenchop. Precautions in managing the crop are necessary to prevent animal losses due to prussic acid (hydrocyanic acid) poisoning. All known sudangrasses and sorghums [S. bicolor (L.) Moench] contain dhurrin [(S)-phydroxymandelonitrile $\beta$-D-glucopyranoside] which yields hydrocyanic acid when hydrolyzed enzymatically in disrupted plant tissues or in the rumen of consuming animals. Breeding sudangrasses with lowered hydrocyanic acid potential (HCN-p) would reduce the danger of hydrocyanic acid poisoning, and permit greater flexibility in the management of this crop. Also, sudangrasses with reduced $\mathrm{HCN}$-p would be useful in the development of sorghum-sudangrass hybrids with lowered HCN-p.

\footnotetext{
'Contribution from USDA-ARS and the Nebraska Agric. Exp. Stn., Lincoln. Published as Paper No. 6173, Journal Series, Nebraska Agric. Exp. Stn. Reccived 18 Feb. 1981. The work reported was conducted under Nebraska Agric. Exp. Stn. Projects 12-088 and 12-114.

"Supervisory research geneticist, USDA-ARS; George Holmes professor of Agronomy, Univ. of Nebraska; and research agronomist, USDA-ARS, Lincoln, NE 68583, respectively.
} 
Breeding for lower HCN-p in sudangrass was facilitated by the recent development of a simple, rapid, nondestructive spectrophotometric procedure (6). This procedure involves the assay of individual first leaves from 7-day-old seedlings grown under controlled conditions. Following completion of the assay, selected seedlings can be transplanted to the field or greenhouse for the production of self or cross-pollinated seed for use in the next cycle of selection.

In a review of studies of the inheritance of cyanogenesis in sudangrass and sorghum, Nass (9) reported that dominant or partially dominant factors were involved in the genetic control of both high and low HCN-p. Most studies suggested multigenic inheritance although one or two major genes also were hypothesized. Hogg and Ahlgren (8) evaluated 175 inbred lines ranging from low to high in HCN content during a 3-year period and reported that HCN content of the lines was stable over years. They also reported that low-HCN strains could be developed by crossing low-HCN inbred lines. Barnett and Caviness (1) reported broad-sense heritability estimates of 0.41 and 0.68 for HCN production in populations derived from two sorghum $X$ sudangrass crosses.

Sorghum is classified as a predominately self-pollinated crop with outcrossing averaging 6\% (10). The outcrossing percentage of sudangrass is usually higher, but reported values vary quite widely. Garber and Atwood (5) observed $76.4,18.2$, and $34.4 \%$ cross-pollination in Pennsylvania for the years 1941, 1942, and 1943, respectively, while Hogg and Ahlgren (8) reported in 1943 that cross-pollination in Wisconsin ranged from 4.5 to $10 \%$. Thus, extensive cross-pollination is possible, but the percentage that occurs in a specific seed field is apparently dependent upon the location, environmental factors, and the type of sudangrass being grown. Recent work by Foster et al. (4) demonstrated positive results for bi-directional mass selection in a grain sorghum population. Thus, selection based on population improvement techniques, developed for use with cross-pollinated crops, may be successfully used with crops such as sorghum that have a very low percentage of cross pollination.

'Greenleaf' sudangrass is used extensively as the male parent in commercial production of sorghum-sudangrass hybrids (7). In 1977, a program of recurrent selection for low and high HCN-p in Greenleaf sudangrass was initiated at the Nebraska Station. The objectives of this research were to evaluate the effectiveness of recurrent selection for increasing or decreasing HCN-p in sudangrass populations, and to develop a reselected Greenleaf strain with lower HCN-p than the parent.

\section{MATERIALS AND METHODS}

All HCN-p values in this study were obtained by use of the spectrophotometric procedure (6). In this procedure, first-leaf samples from week-old seedlings were weighed, and dhurrin was extracted and hydrolyzed by autoclaving the samples in water. Aliquots of the extracts were then diluted in base, and absorbance was read at $330 \mathrm{~nm}$, the absorption maximum of $p$-hydroxybenzaldehyde. HCN-p values were derived from the $330 \mathrm{~nm}$ absorbance $\left(A_{330}\right)$ readings by simple calculations $(6)$.

The initial population consisted of 184 seedlings of the cultivar Greenleaf grown from Kansas foundation seed. From this initial population, 19,17, and 17 seedlings were selected to represent the lowest, intermediate, and highest HCN-p levels in further studies. The selected seedlings were transplanted to the field, heads were bagged prior to anthesis, and selfed seed was harvested. Five plants from each HCN-p group with adequate supplies of selfed seed were selected for further study. Seven replications of the seed from the 15 selected plants were planted for assay of $\mathrm{HCN}$-p. A total of $1405 \mathrm{~S}_{1}$ seedlings were assayed with a range of 81 to 110 per line. This phase of the study will be referred to as cycle 0 .

For the next step, cycle 1, only those seedlings with the highest and lowest levels of $\mathrm{HCN}$-p were selected from the total of $1405 \mathrm{~S}_{1}$ seedlings obtained from the 15 original plants. Selections were made across all replications and without regard to the original HCN-p group (high, medium, or low) from which the seedling originated. Thus, the 26 seedlings selected for lowHCN-p included 14,9 , and 3 seedlings from the low, medium, and high-HCN-p groups, respectively. Similarly, the 23 seedlings selected for high-HCN-p included 9, 5, and 9 seedlings from the low, medium, and high-HCN-p groups, respectively.

The low and high-HCN-p populations were transplanted to separate field isolations in 1978, with plants on 61 -cm centers. Open-pollinated seed was harvested from individual plants. Three replications of 10 seedlings each from each line (i.e., from each parent plant) were assayed for HCN-p. Greenleaf was included in each replication as a control.

Plants for the next cycle of selection (cycle 2) were selected from individual seedlings of the 8 lines whose mean HCN-p was lowest among the 26 low-HCN-p lines, and from the highest 8 lines among the 23 high-HCN-p lines. The selected low and high-HCN-p populations included 54 and 56 plants, respectively. Each population was transplanted to a separate field isolation in 1979, with plants randomized on 107-cm centers. A severe infestation of chinch bugs [Blissus leucopterus leucopterus (Say)] destroyed some plants in the low-HCN-p isolation; seed was produced on only 33 of these plants. Open-pollinated seed was harvested from individual plants, and three replications of 10 seedlings from each plant that produced sufficient seed (31 plants from the low-HCN-p isolation and 55 from the highHCN-p isolation) were assayed for HCN-p. Greenleaf was included in each replication as a check. The breeding procedures used and the time period covered by each cycle are summarized in Table 1.

A narrow-sense heritability estimate was obtained by the regression of offspring produced by selfing on their parents in cycle 0 . In this situation, $b_{o p}$, the regression of offspring on parents, was used as the heritability estimate $\left(\mathrm{H}_{\mathrm{b}}\right)$. Realized heritability estimates $(\mathrm{Hr})(3)$ were also determined for cycles 0,1 , and 2 using the following equation: $\mathrm{Hr}=\left(\overline{\mathrm{X}}_{\mathrm{oh}}-\overline{\mathrm{X}}_{\mathrm{o}, 1}\right) /\left(\overline{\mathrm{X}}_{\mathrm{ph}}-\right.$ $\left.\overline{\mathrm{X}}_{\mathrm{p} 1}\right)$ where the $\overline{\mathrm{X}}$ 's are means and the subscripts, o, p, h, and 1 are offspring, parent, high and low, respectively.

Variance components from the analyses of the replicated tests of the progeny of each cycle were used to calculate the ratio: $\mathrm{Hv}$ $=\sigma^{2} \mathrm{~g} / \sigma^{2} \mathrm{~g}+\sigma^{2} \mathrm{e}$ ) where $\sigma^{2} \mathrm{~g}$ and $\sigma^{2}$ eare the genetic and environmental components of variance, respectively. This ratio was difficult to interpret for this study because it was unknown whether the parents were homozygous or heterozygous individuals or whether the progenies were the products of crossing, selfing, or both. It is an estimate, however, of the variance among lines that is due to genotypic differences and as such can be used as a broad-sense heritability estimate.

Gain from selection (Gs) was calculated both as a deviation from Greenleaf $\left(\mathrm{G}_{\mathrm{st}}\right)$ and as a deviation percentage from Greenleaf $\left(G_{\mathrm{sp}}\right)$ for cycles 1 and 2 . The equations used were as follows:
(a) $\mathrm{G}_{\mathrm{sd}}$ for low HCN-p $=\left(\overline{\mathrm{X}}_{\mathrm{g}}-\overline{\mathrm{X}}_{\mathrm{ol}}\right)$.
(b) $\mathrm{G}_{\mathrm{sd}}$ for high HCN-p $=\left(\mathrm{X}_{\mathrm{nh}}-\mathrm{X}_{\mathrm{g}}\right)$.
(c) $G_{\mathrm{sp}}$ for low HCN-p $=\left(\overline{\mathrm{X}}_{\mathrm{v}}-\overline{\mathrm{X}}_{\mathrm{ol}}\right) / \overline{\mathrm{X}}_{\mathrm{g}} \times 100$.
(d) $G_{s p}$ for high HCN-p $=\left(\bar{X}_{c h}-\frac{o 1}{X_{g}}\right) / \bar{X}_{g} \times 100$. 
Table 1. Means, standard deviations, and ranges for HCN-p of parents and their progenies for two cycles of divergent selection for HCN-p in Greenleaf sudangrass.

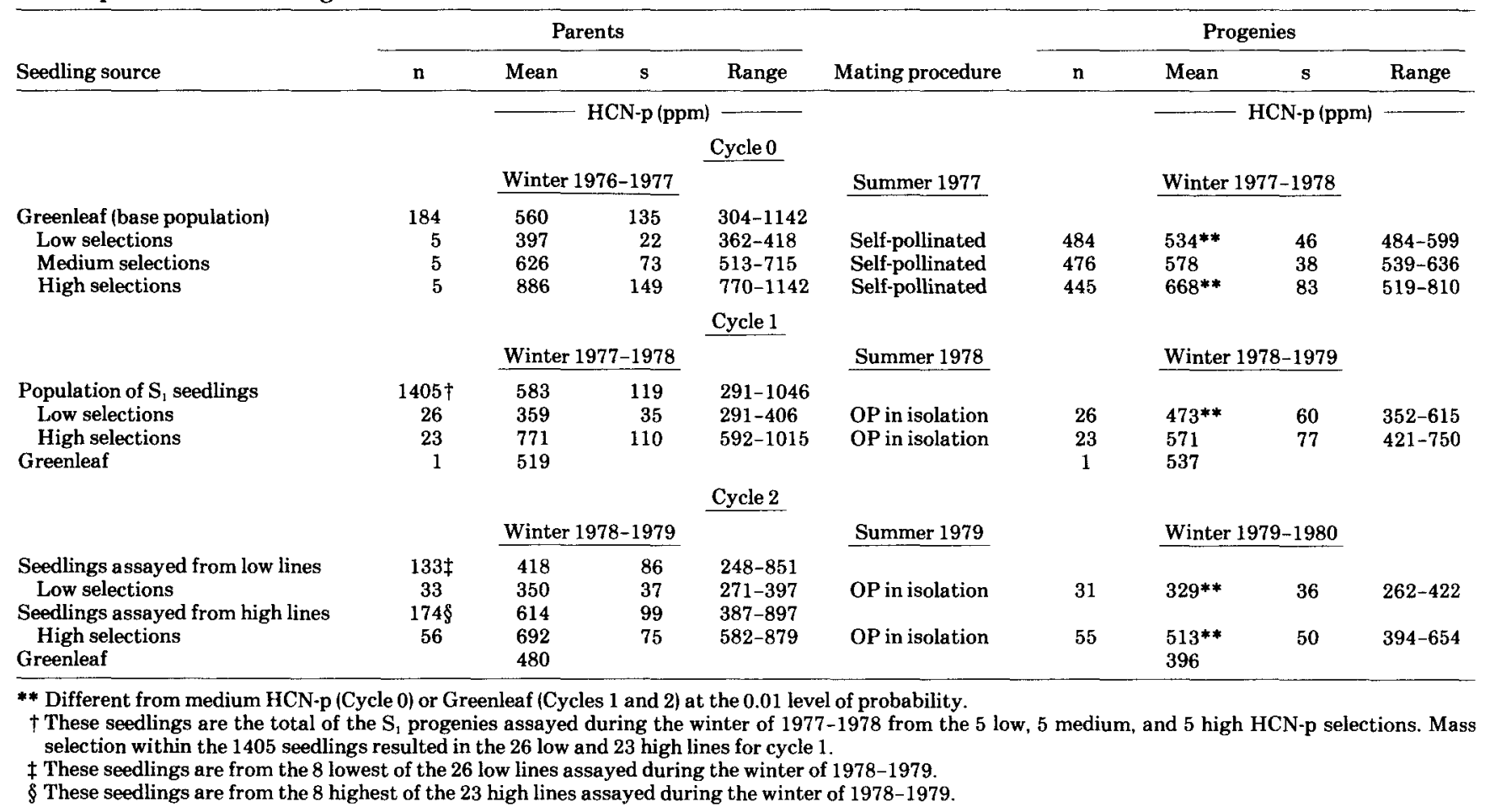

The subscript $\mathrm{g}$ is for Greenleaf; the others are the same as those used for the realized heritability equations.

Leaf weight of seedlings was determined during the HCN assay procedure. Statistical analyses of leaf weight of progenies of plants selected for high and low HCN-p were also conducted using analyses of variance procedures for all three cycles. Phenotypic and genotypic correlations of $\mathrm{HCN}-\mathrm{p}$ and leaf weight were determined using the following equations (3): (a) Phenotypic correlations $=r_{i j}=M_{i j} /{ } M_{i i} \times M_{i j}$ where $M P_{i j}$ is the mean product of HCN-p and leaf weight, respectively, and $\mathrm{MS}_{\mathrm{ii}}$ and $\mathrm{MS}_{\mathrm{ji}}$ are their respective mean squares; and (b) Genotypic correlation $=\mathrm{rg}_{\mathrm{ij}}=\sigma \mathrm{g}_{\mathrm{ij}} / \sqrt{ } \sigma^{2} \mathrm{~g}_{\mathrm{ii}} \times \sigma^{2} \mathrm{~g}_{\mathrm{j}}$ where $\sigma \mathrm{g}_{\mathrm{ij}}$ is the genetic covariance of $\mathrm{HCN}$-p and leaf weight, respectively, and $\sigma^{2} g_{i i}$ and $\sigma^{2} g_{i j}$ are their respective genetic variances.

In each cycle, planned treatment comparisons were used to compare the ranked means of the low, check, and high populations. Within each cycle, however, not all of the comparisons were orthogonal.

\section{RESULTS AND DISCUSSION}

The first part of this study, cycle 0 , was used to determine the effectiveness of the seedling assay procedure as a screening test for HCN-p. There were significant differences among the progenies of selected self-pollinated plants (Table 1). The progenies of the high-HCN-p parent plants were significantly higher in HCN-p than the progenies of the medium-HCN-p group which were higher than the progenies of the low-HCN-p group.

Seedlings for cycle 1 were selected from the entire population of $1405 \mathrm{~S}_{1}$ seedlings screened in cycle 0 . This procedure broadened the germplasm base for the ensuing cycles of selection, but it also negated the gain from selection made for low and high HCN-p in cycle 0 .

In cycle 1 , the mean of the 23 progenies of the highHCN-p population (following open-pollination in isolation) was higher than for Greenleaf (Table 1) but the difference was significant only at the 0.12 level of probability. However, Greenleaf was significantly $(0.01$ level of probability) higher in HCN-p than the mean of the 26 progenies of the low-HCN-p population. In cycle 2, the mean of the 55 progenies of the high-HCN-p population was significantly higher in HCN-p than Greenleaf, and Greenleaf was significantly higher than the mean of the 31 progenies of the low-HCN-p population.

Narrow sense and realized heritability estimates for HCN-p were 0.32 and 0.28 , respectively, for cycle 0 (Table 2). The realized heritability estimate for cycle 1 was only slightly lower than the value for cycle 0 but the estimate for cycle 2 was almost twice the cycle 0 value. With the selection procedures used, gain from selection was a function of only the additive genetic variance (2). Realized heritability thus estimates heritability in the narrow sense. Average realized heritability was 0.40 for the two cycles. This was considerably lower than the broad-sense heritability estimates obtained from each cycle, indicating that non-additive genetic effects are probably quite important in determining HCN-p in sudangrass.

After two cycles of selection, the low-HCN-p population differed from Greenleaf by about $17 \%$ while the highHCN-p population differed by almost $30 \%$ (Table 2). More gain from selection was made in the low-HCN-p population in cycle 1 than in the high-HCN-p population, but the reverse was true in cycle 2 .

In cycle 0 , mean leaf weights of 15.5 and $15.6 \mathrm{mg}$ for the progenies of the high and low-HCN-p parents, respectively, did not differ significantly. Similarly, in cycle 1 , the respective weights of 18.3 and 17.4 were not significantly different. In cycle 2 , the progenies of the 
Table 2. Heritability estimates for HCN-p, gain from divergent selection for $\mathrm{HCN}$-p, and genotypic and phenotypic correlations of HCN-p with first-leaf weight in Greenleaf sudangrass.

\begin{tabular}{|c|c|c|c|}
\hline & \multicolumn{3}{|c|}{ Selection cycle } \\
\hline & Cycle 0 & Cycle 1 & Cycle 2 \\
\hline \multicolumn{4}{|c|}{ Heritability estimates } \\
\hline $\begin{array}{l}\text { Narrow-sense }\left(\mathrm{H}_{\mathrm{b}}\right) \\
\text { Realized }\left(\mathrm{H}_{\mathrm{r}}\right) \\
\text { Broad-sense }\left(\mathrm{H}_{\mathrm{v}}\right)\end{array}$ & $\begin{array}{l}0.32 \\
0.28 \\
0.81\end{array}$ & $\begin{array}{l}0.24 \\
0.82\end{array}$ & $\begin{array}{l}0.55 \\
0.89\end{array}$ \\
\hline \multicolumn{4}{|l|}{ Gain from selection } \\
\hline $\begin{array}{l}\text { Actual } G_{\text {sd }}(\mathrm{ppm}) \\
\text { Low HCN-p } \\
\text { High HCN-p }\end{array}$ & & $\begin{array}{l}64 \\
34\end{array}$ & $\begin{array}{r}68 \\
117\end{array}$ \\
\hline $\begin{array}{l}\text { Percentage gain } \mathrm{G}_{5} \\
\text { Low HCN-p } \\
\text { High HCN-p }\end{array}$ & & $\begin{array}{r}11.9 \\
6.3\end{array}$ & $\begin{array}{l}17.2 \\
29.5\end{array}$ \\
\hline \multicolumn{4}{|c|}{ Correlations of HCN-p and first leaf weight } \\
\hline $\begin{array}{l}\text { Phenotypic } r_{i j} \\
\text { Genotypic } r_{\text {gij }}\end{array}$ & $\begin{array}{l}-0.03 \\
-0.03\end{array}$ & $\begin{array}{r}-0.06 \\
0.10\end{array}$ & $\begin{array}{l}-0.35^{* *} \\
-0.36\end{array}$ \\
\hline
\end{tabular}

** Indicates significance at the 0.01 level of probability.

high-HCN-p seedlings were significantly lower in leaf weight than the progenies of the low-HCN-p seedlings. The difference, however, was small (18.6 vs. $19.5 \mathrm{mg}$ ).

Phenotypic and genotypic correlations for HCN-p and leaf weight were very low for cycles 0 and 1 (Table 2). In cycle 2 , however, there was a negative correlation between HCN-p and leaf weight. This relationship may be advantageous from an agronomic standpoint, for it suggests that low-HCN-p seedlings have relatively large first leaves which may be associated with improved seedling vigor.

These results indicate that substantial progress was made in changing the HCN-p of Greenleaf sudangrass in two cycles of selection using breeding procedures developed for cross-pollinated crops. Foster et al. (4) also found that mass selection produced significant divergence of population means for three traits in grain sorghum, which is a predominantly self-pollinated crop. Continued selection for low HCN-p may produce a Greenleaf strain that can be safely utilized at all stages of growth, but animal evaluations will be needed to determine when a safe level has been attained.

\section{REFERENCES}

1. Barnett, R. D., and C. E. Caviness. 1968. Inheritance of hydrocyanic acid production in two sorghum $\times$ sudangrass crosses. Crop Sci. 8:89-91.

2. Empig, L. T., C. O. Gardner, and W. A. Compton. 1971. Theoretical gains for different population improvement procedures. Nebraska Agric. Exp. Stn. Misc. Pub. 26.

3. Falconer, D. S. 1960. Introduction to quantitative genetics. Ronald Press Co., New York.

4. Foster, K. W., S. K. Jain, and D. G. Smeltzer. 1980. Responses to 10 cycles of mass selection in an inbred population of grain sorghum. Crop Sci. 20:1-4.

5. Garber, R. J., and S. S. Atwood. 1945. Natural crossing in sudan grass. J. Am. Soc. Agron. 37:365-369.

6. Gorz, H. J., W. L. Haag, J. E. Specht, and F. A. Haskins. 1977. Assay of $p$-hydroxybenzaldehyde as a measure of hydrocyanic acid potential in sorghums. Crop Sci. 17:578-582.

7. Harvey, P. H. 1977. Sorghum germplasm base in the United States p. 186-198. In Proc. of the 32nd Annual Corn and Sorghum Research Conference, Chicago, Ill. 6-8 Dec. 1977. Am. Seed Trade Assoc., Washington, D.C.

8. Hogg, P. G., and H. L. Ahlgren. 1943. Environmental, breeding, and inheritance studies of HCN in Sorghum vulgare var. sudanense. J. Agric. Res. 67:195-210.

9. Nass, Hans G. 1972. Cyanogenesis: Its inheritance in Sorghum bicolor, Sorghum sudanense, Lotus, and Trifolium repens-a review. Crop Sci. 12:503-506

10. Poehlman, J. M. 1959. Breeding Field Crops. Henry Holt and Company, Inc. New York 